\title{
Complete repair of Ebstein anomaly in neonates and young infants: A 16-year follow-up
}

\author{
Umar S. Boston, MD, ${ }^{\text {a }}$ Steven P. Goldberg, MD, ${ }^{\mathrm{a}}$ Kent E. Ward, MD, ${ }^{\mathrm{d}}$ Edward D. Overholt, MD, ${ }^{\mathrm{d}}$ \\ Thomas Spentzas, MD, MS, ${ }^{\mathrm{c}}$ Thomas K. Chin, MD, ${ }^{\mathrm{b}}$ and Christopher J. Knott-Craig, MD $^{\mathrm{a}}$
}

Objective: The purpose of this study was to review the long-term outcome of patients with Ebstein anomaly who underwent complete repair as neonates and young infants.

\begin{abstract}
Methods: Between March 1994 and May 2010, 32 patients (23 neonates and 9 young infants) underwent surgery for Ebstein anomaly. Mean weight was $3.9 \pm 2.0 \mathrm{~kg}$ (range, 1.9-8.6 kg). The Great Ormond Street Echocardiography score was greater than 1.5 in 22 of the 23 neonates and greater than 1.0 in all infants. All associated cardiac defects were repaired including pulmonary atresia in 15 and ventricular septal defect in 4 . Primary outcome measures included (1) early and late survival, (2) freedom from reoperation, (3) durability of tricuspid valve repair, and (4) functional status.
\end{abstract}

Results: Early survival was $78.1 \%$ (25/32). There was 1 late death. Fifteen-year survival estimate was $74 \% \pm$ $8 \%$. For patients with pulmonary atresia, early and late survival was $60 \% \pm 12 \%(9 / 15)$ versus $94.1 \%(16 / 17)$ $(P<.05)$, respectively; for those without pulmonary atresia, early and late survival was $60 \% \pm 12 \%$ versus $85 \%$ $\pm 10(P=.06)$, respectively. The mean follow-up was $5.9 \pm 4.5$ years $(0.1-16$ years $)$. A biventricular repair was achieved in $90.6 \%$ (29/32) patients. Median preoperative tricuspid regurgitation was $4 / 4$ and at late follow-up, $1 /$ 4. Freedom from reoperation at 15 years was $74 \% \pm 10 \%$ for patients undergoing biventricular repair. All survivors are in New York Heart Association class I or II.

Conclusions: Biventricular repair of Ebstein anomaly in symptomatic neonates is feasible with good early and late survival, especially in those without pulmonary atresia. Tricuspid valve repair is durable, and functional status is excellent. (J Thorac Cardiovasc Surg 2011;141:1163-9)

Earn CME credits at

http://cme.ctsnetjournals.org

Ebstein anomaly (EA) is a rare congenital heart defect that results from varying degrees of failure of delamination of the tricuspid valve (TV) leaflets from the endocardium of the right ventricle (RV). ${ }^{1}$ This results in apical displacement, particularly of the septal and posterior leaflets of the TV. The anterior leaflet is typically broad and sail-like and is based at the true annulus. The $\mathrm{RV}$ is also myopathic, with a reduced func-

\footnotetext{
From the Divisions of Pediatric Cardiothoracic Surgery, ${ }^{\mathrm{a}}$ Pediatric Cardiology, ${ }^{\mathrm{b}}$ Critical Care Medicine and Epidemiology, ${ }^{\mathrm{c}}$ University of Tennessee Health Sciences Center/Le Bonheur Children's Hospital, Memphis, Tenn; and the Division of Pediatric Cardiology, ${ }^{\mathrm{d}}$ University of Oklahoma Health Sciences Center, Oklahoma City, Okla.

Disclosures: Authors have nothing to disclose with regard to commercial support.

Read at the 36th Annual Meeting of The Western Thoracic Surgical Association, Ojai, California, June 23-26, 2010.

Received for publication June 17, 2010; revisions received Jan 3, 2011; accepted for publication Jan 19, 2011; available ahead of print Feb 28, 2011.

Address for reprints: Umar S. Boston, MD, Le Bonheur Children's Hospital, $50 \mathrm{~N}$ Dunlap St, Suite 2598, Memphis, TN 38103 (E-mail: uboston@uthsc.edu). $0022-5223 / \$ 36.00$

Copyright (c) 2011 by The American Association for Thoracic Surgery doi:10.1016/j.jtcvs.2011.01.029
}

tional portion as a result of atrialization. ${ }^{2}$ Age at presentation can vary from neonate to adulthood. ${ }^{3,4}$ Symptoms in the neonate result from a combination of TV regurgitation, RV dysfunction, inadequate left ventricular filling owing to ventricular septal bowing, inadequate pulmonary blood flow, and arrhythmias. Mortality rates for symptomatic neonates with EA are extraordinarily high. ${ }^{6}$ Neonates with Great Ormond Street Echocardiogram (GOSE) scores greater than 1.5 , or greater than 1.1 with associated cyanosis, have a mortality approaching $100 \% .^{4,6}$ In addition, neonates with severe cardiomegaly with a cardiothoracic ratio greater than 0.8 , those with severe TV regurgitation, and acyanotic neonates with a GOSE score greater than 1.0 associated with functional pulmonary atresia (PA) and a large atrial septal defect (ASD) also have a dismal prognosis. ${ }^{3,6,8}$ Surgical approaches for the management of these critically ill neonates have varied across institutions and include the Starnes RV exclusion procedure, systemicpulmonary shunts, hybrid-type procedures, and heart transplantation. ${ }^{9-16}$ Single-ventricle palliation, first reported by Starnes and associates ${ }^{9}$ in 1991, provided surgeons with the first reproducible surgical procedure for symptomatic neonates with EA and found wide acceptance in the pediatric caregiver community. In 2000, Knott-Craig and associates ${ }^{12}$ published the first series of biventricular repairs (BVRs) in 


$$
\begin{aligned}
& \text { Abbreviations and Acronyms } \\
& \text { ASD }=\text { atrial septal defect } \\
& \text { BVR }=\text { biventricular repair } \\
& \text { EA }=\text { Ebstein anomaly } \\
& \text { GOSE }=\text { Great Ormond Street Echocardiogram } \\
& \text { PA }=\text { pulmonary atresia } \\
& \text { PS }=\text { pulmonary stenosis } \\
& \text { RV } \quad \text { right ventricle } \\
& \text { RVOT } \\
& \text { TV right ventricular outflow tract } \\
& \text { = tricuspid valve }
\end{aligned}
$$

neonates with a $12 \%$ mortality in 8 patients followed up for 5 years. $\mathrm{We}^{12,14,17}$ have subsequently reported our surgical technique, perioperative management strategy, and early results illustrating the feasibility of performing a BVR in critically ill neonates and infants with EA.

The purpose of this study was to examine the long-term results in these patients who have undergone BVR as the primary definitive operation either during the neonatal period or early infancy.

\section{PATIENTS AND METHODS Study Design}

Between March 1994 and May 2010, 44 consecutive symptomatic neonates with $\mathrm{EA}$ were referred to the senior authors (C.K.C., $\mathrm{n}=43$; U.S.B., $\mathrm{n}=1$ ) for surgical evaluation. These patients were managed at Children's Hospital of Oklahoma, Oklahoma City, Oklahoma (1994-2006), University of Alabama at Birmingham, Birmingham, Alabama (2006-2008), and Le Bonheur Children's Hospital, Memphis, Tennessee (2008-2010).

Of these 44 neonates, 2 died immediately after delivery despite perinatal resuscitative efforts. Another 19 neonates could be successfully managed initially without surgery by a combination of prostaglandins, nitric oxide, intermittent positive-pressure ventilation, and inotropic support as previously described. ${ }^{12,13}$ Although these patients were ultimately discharged from the hospital, 9 required surgical intervention during early infancy. The remaining 23 critically ill neonates with EA required urgent surgical intervention during the neonatal period. These 23 neonates and the 9 young infants who were initially discharged comprise the study cohort $(\mathrm{n}=32)$.

A diagnosis of EA was made by echocardiography using standard criteria. ${ }^{1-3}$ Displacement of the septal leaflet was greater than $8 \mathrm{~mm} / \mathrm{m}^{2}$ in most cases as assessed by echocardiography. In 3 patients the posterior leaflet was predominantly displaced rather than the usual septal leaflet. TV regurgitation was assessed quantitatively by color Doppler using a scale of 0 (none) to 4 (severe). The GOSE score $e^{4,6,14}$ was calculated as the sum of the combined area of the right atrium and atrialized RV, divided by the area of the sum of the functional RV and the left atrium and left ventricle. Additional cardiac defects were assessed by echocardiography. Patients with atrioventricular discordance associated with EA were not included in the study group.

Primary outcome measures included (1) early and late survival, (2) freedom from reoperation, (3) durability of TV repair, (4) functional status (New York Heart Association class), and (5) need for long-term antiarrhythmic medication.

\section{Study Group $(\mathbf{n}=32)$}

Thirty-two patients with EA underwent surgical intervention during the study period. There were 23 neonates and 9 infants. Seventeen were male
$(17 / 32 ; 53 \%)$. Median age at the time of the operation was 15 days. Mean weight was $3.9 \pm 2.0 \mathrm{~kg}$. The smallest neonate weighed $1.9 \mathrm{~kg}$ at a gestational age of 34 weeks with associated anatomic PA. Mean cardiothoracic ratio was $0.92 \pm 0.02$. The GOSE score was greater than $1.5(4 / 4)$ in 22 of 23 neonates and greater than $1.0(3-4 / 4)$ in all infants. Thirteen neonates and 2 infants had associated anatomic PA. In addition, there was one 5-week-old infant with high-grade pulmonary stenosis (PS).

Complete BVR consisted of the following 5 aspects: (1) The technique of TV repair evolved during the course of the study period, as experience was gained and prior errors were recognized and modified. Initially, a Danielson-type repair ${ }^{11}$ was used when the anterior leaflet was well developed and mobile. Later, the TV repair was effected at the level of the coapting leaflets of the TV rather than at the true annulus. Finally, a Sebeningtype suture ${ }^{18}$ was added to fix the major papillary muscles of the anterior leaflet to the interventricular septum to minimize the effects of pulmonary hypertension in the early postoperative period. Often the TV leaflets were underdeveloped, curtained, or dysplastic, making each repair somewhat unique. (2) Reduction right atrioplasty was done to allow for lung expansion and more efficient cardiac function. (3) The obligatory ASD was partially closed, leaving a 3-mm fenestration to allow for right-to-left shunting in the presence of postoperative RV dysfunction. (4) An adequate RV outflow tract (RVOT) was constructed for patients with anatomic PA or PS. Different techniques were used for this: Initially, small transannular patches using untreated autologous pericardium were used to create an RVOT of about $7 \mathrm{~mm}$ in diameter. Later in our experience, aortic homografts were used more liberally. (5) All concomitant cardiac defects were repaired at the time of the operation (Table 1).

\section{Preoperative Management and Surgical Indications}

These critically ill patients were all initially managed in the intensive care unit. Our perioperative strategy for these neonates has previously been reported. ${ }^{12-14}$ Adequate sedation and paralysis were initially provided to lower pulmonary vascular resistance and mean airway pressures. Inotropic support in the form of dopamine or isoproterenol was initiated to improve cardiac output. Prostaglandin infusion was necessary for patients with anatomic PA or PS or those with elevated pulmonary vascular resistance. Inhaled nitric oxide was also used to reduce pulmonary vascular resistance. Daily echocardiograms were used to assess the development of prograde pulmonary blood flow.

Indications for early surgical intervention included persistent ventilator dependency, right heart failure unresponsive to medical therapy, severe TV regurgitation associated with cyanosis, persistent need for significant intravenous inotropic support, and persistent prostaglandin- dependent circulation.

\section{Surgical Repair}

Twenty-nine patients had a complete BVR $(29 / 32,90.6 \%)$ during the neonatal period or infancy. Details of the repairs have been previously

TABLE 1. Comorbidities and associated cardiac defects

\begin{tabular}{lr}
\hline Single or multiple VSD & 4 \\
Anatomic PA & 15 \\
Functional PA & 7 \\
Mechanical ventilation & 20 \\
Hepatorenal failure & 5 \\
Diffuse coagulopathy & 2 \\
Intracranial hemorrhage grade III or IV & 3 \\
Hypoplastic branch pulmonary arteries & 2 \\
Small LV & 3 \\
Malignant tachyarrhythmias & 4 \\
\hline
\end{tabular}

$V S D$, Ventricular septal defect; $P A$, pulmonary atresia; $L V$, left ventricle. 
published. ${ }^{12,14,17}$ Salient features of the repairs are indicated under subheadings of TV repair and management of the RVOT in PA.

TV repair. TV repair was done in 26 patients. TV repair was unnecessary in 1 patient because only mild tricuspid regurgitation was present, and 2 patients required initial TV replacement. One neonate was transferred moribund after a failed Starnes RV exclusion procedure. At operation, the patch from the exclusion procedure was taken down, and the heart was fully septated. The TV was replaced with a mechanical prosthesis and the RVOT reconstructed with an aortic homograft. Eight months later the partly thrombosed mechanical prosthesis was replaced with a bioprosthesis and a bidirectional Glenn anastomosis added to improve the longevity of the bioprsthesis. This patient is currently asymptomatic 10 years later.

The second neonate was transferred from an outside facility after undergoing TV repair followed by TV replacement, which was complicated by complete heart block. Before his transfer, he also underwent device closure of a large ASD for hypoxemia and balloon fracture of the tricuspid bioprosthesis secondary to prosthetic valve obstruction. At operation, the ASD device was removed and the atrial septum closed, and the malfunctioning TV prosthesis was replaced with a functioning bioprosthesis. This patient is currently asymptomatic 8 years later.

The surgical techniques for TV repair have previously been fully reported. ${ }^{13,14,17}$ A Danielson-type repair was done in 10 patients, a DeVega posterior annuloplasty in 10 , anterior leaflet extension in 1 , and a combination of annuloplasty and closure of leaflet fenestrations in 5 patients. A Sebening stitch was added to the TV repair in 5 of the last 7 patients. ${ }^{18,19}$

Three patients did not have BVR: (1) An infant with associated anatomic PA and badly scarred hypoplastic pulmonary arteries was transferred to our facility after 4 prior sternotomies for systemic-pulmonary shunts and revisions. At operation, the pulmonary arteries were augmented from hilum to hilum using pulmonary homograft patches, and a bidirectional Glenn shunt was placed. The associated PA was not addressed. This patient is currently being evaluated for $1 \frac{1}{2} 2$-ventricle repair. (2) A neonate with anatomic PA, diminutive functional RV, and rudimentary TV leaflets not amenable to repair was palliated with a Starnes RV exclusion procedure. This patient has subsequently undergone a successful bidirectional Glenn and completion Fontan operation. (3) A neonate with anatomic PA and mild tricuspid regurgitation underwent a systemic-pulmonary shunt only and has subsequently undergone bidirectional Glenn anastomosis. The functional $\mathrm{RV}$ was diminutive and unsuitable for BVR. This patient is currently awaiting Fontan completion.

All concomitant cardiac defects were repaired in patients having BVR (Table 1). This included closure of single or multiple VSDs in 4 patients.

Management of RVOT. Fifteen patients had anatomic PA. Highgrade PS was present in 1 additional patient. Functional PA was present at the time of surgery in another 7 patients.

Early in our experience, anatomic PA was repaired with a transannular patch $(\mathrm{n}=8)$ or open pulmonary valvotomy $(\mathrm{n}=1)$. Two of these patients required postoperative support with extracorporeal membrane oxygenation; they were later taken back to the operating room and the transannular patch was replaced with a homograft. Because the hemodynamics were so much better after placement of the homograft in the RVOT, even though both these patients later died during the postoperative period, we subsequently elected to repair anatomic PA with a small homograft in 3 further patients, all of whom have survived.

Two patients who underwent BVR required a systemic-pulmonary shunt for additional pulmonary blood flow. The need for a systemic-pulmonary shunt was due to diminutive pulmonary arteries in 1 patient and a very small functional RV in the other. Both were placed after weaning from cardiopulmonary bypass, and hypoxemia was evident.

A bidirectional Glenn procedure was done in 5 patients who underwent BVR. This was added to 4 of 9 infant repairs (all $>3$ months old at time of repair) and added to a neonatal repair at 7 months of age secondary to residual moderate tricuspid regurgitations. In 1 of the patients the bidirectional Glenn shunt was taken down during the perioperative period because of systemic venous hypertension. A bidirectional Glenn procedure was also the second-stage palliation in the 3 patients stratified to a singleventricle pathway.

\section{Follow-up}

Medical records were reviewed to obtain clinical, surgical, and perioperative data. Long-term follow-up data were obtained via clinic visits, telephone interviews, echocardiography, and catheterization data, and follow-up was done with full approval by the institutional review board. Follow-up extends up to 16 years and is complete in $93 \%$ of patients. The mean follow-up was $5.9 \pm 4.5$ years.

\section{Statistical Method}

The data are presented as mean \pm standard deviation for the normally distributed variables and median with interquartile range for the non-normally distributed variables. Normally distributed continuous variables (paired) were compared by the paired $t$ test, and non-normally distributed variables were compared by the Wilcoxon test. Categorical variables were compared by Fisher's exact test owing to small counts. We tested whether the presence of PA or the need for extracorporeal membrane oxygenation were predictors of mortality. The Kaplan-Meier cumulative survival and need for reoperation estimates were assessed for all patients with EA treated with BVR. The Kaplan-Meier percentiles are expressed as mean \pm standard error. The data were analyzed with R 2.10 .1 software, package "survival," and all the results were validated with SPSS 17 (SPSS, Inc, Chicago, Ill).

\section{RESULTS \\ Early Survival}

Early survival was $78.1 \%$ (25/32). For patients with and without PA, early survival was $60 \%(9 / 15)$ versus $94.1 \%$ $(16 / 17)(P=.05)$. For patients undergoing BVR $(n=29)$, early survival was $76 \% \pm 10 \%$. Early survival among neonates needing surgery was $69.5 \%(16 / 23)$.

There were no early survivors among the neonates $(\mathrm{n}=3)$ who needed extracorporeal membrane oxygenation postoperatively $(P=.01)$. All of these neonates had anatomic PA, and the mode of death was cardiac failure with RV distention in 2 and persistent bleeding in 1. Two of them were taken back to surgery and the transannular patch replaced with an aortic homograft. Although the hemodynamics were much improved postoperatively, 1 patient had a grade IV intracranial hemorrhage and care was withdrawn, and the other died of persistent coagulopathy.

All neonates with grade 3-4 intracranial hemorrhage before initial repair $(\mathrm{n}=3)$ died, and those in whom highgrade intracranial hemorrhage developed postoperatively $(\mathrm{n}=2)$ also died $(P=.01)$.

The 3 patients who were stratified to a single-ventricle pathway all survived initial palliation and are well at late follow-up after having undergone a bidirectional Glenn procedure.

\section{Late Survival}

There has been 1 late death. The 15 -year survival estimate for the entire study group $(n=32)$ was $74 \% \pm 8 \%$ (Figure 1). The single late death resulted from respiratory 


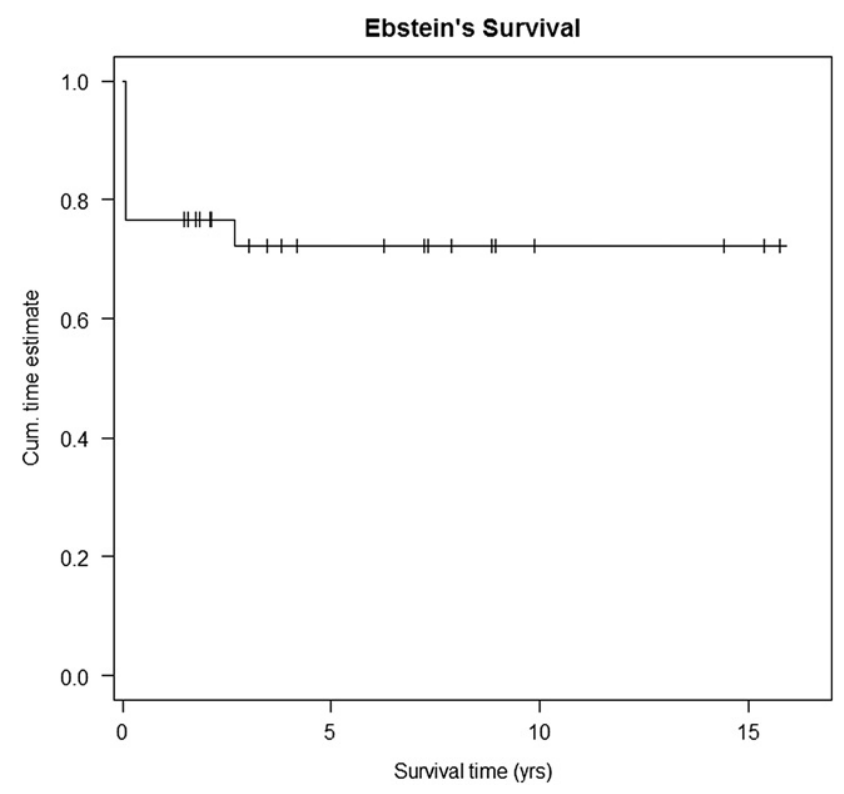

FIGURE 1. Kaplan-Meier survival estimate for all patients with Ebstein anomaly $(\mathrm{n}=32)$.

syncytial viral pneumonia 2 years later in a patient with known bronchopulmonary dysplasia as a preterm infant. For the patients having a BVR $(\mathrm{n}=29), 15$-year survival was $72 \% \pm 9 \%$ (Figure 2). For patients with and without PA, 15-year survival was $60 \% \pm 12 \%$ and $85 \% \pm 10 \%$ $(P=.06)$. In the subgroup of neonates with and without PA, the 15 -year survival estimate was $40 \% \pm 15 \%$ versus $79 \% \pm 13 \%(P=.03)$ (Figure 3$)$.

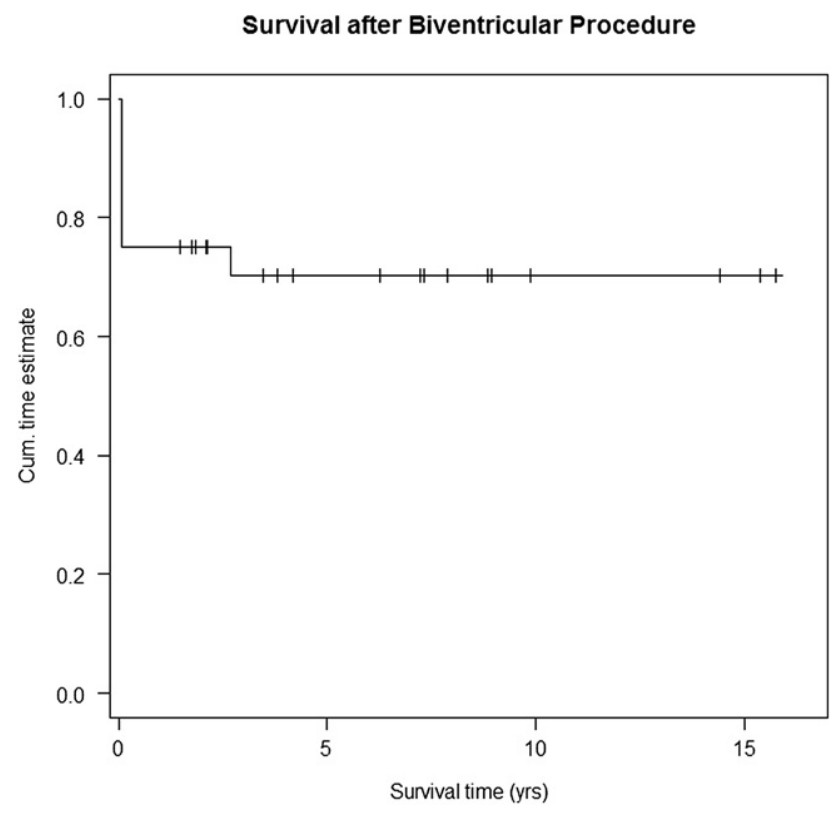

FIGURE 2. Survival after biventricular repair for Ebstein anomaly $(\mathrm{n}=29)$.

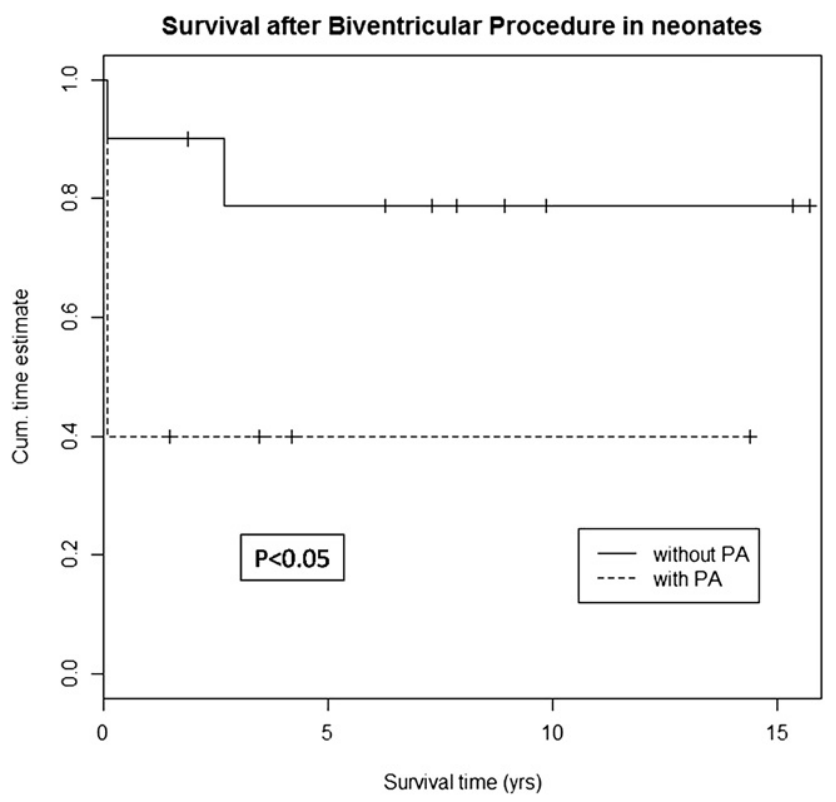

FIGURE 3. Comparison of survival for neonates undergoing biventricular repair with $(\mathrm{n}=11)$ and without $(\mathrm{n}=10)$ anatomic pulmonary atresia $(P A)$ $(P=.03)$.

\section{TV Function and Durability}

The TV z-score preoperatively was $3.1 \pm 1.6$. In patients undergoing TV repair, the mean reduction in TV annulus was $10.4 \pm 5.2 \mathrm{~mm}$. Median severity of TV regurgitation preoperatively was $4 / 4$ and at late follow-up, $1 / 4$. This was a highly significant improvement $(P=.01)$

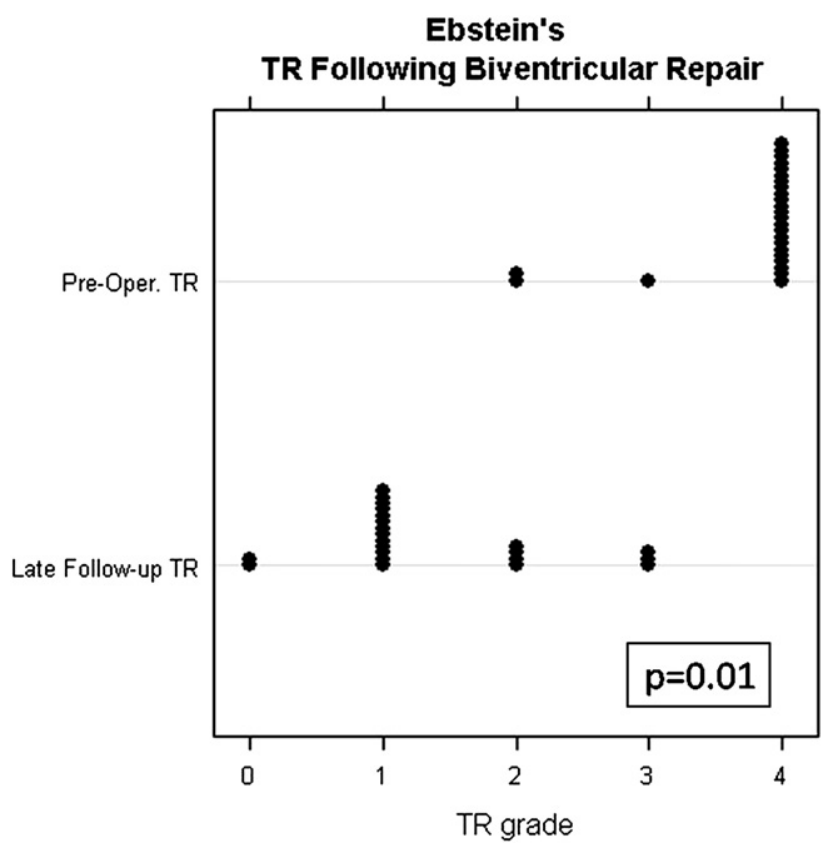

FIGURE 4. Severity of tricuspid valve regurgitation before repair and at late follow-up. Severity grades: $0=$ none, $1=$ mild, $2=$ mild plus, $3=$ moderate, and $4=$ severe. 
(Figure 4). Progressive TV stenosis has not been evident in the follow-up period for patients undergoing BVR.

\section{Freedom From Reoperation}

The patients having a palliative procedure $(n=3)$ have all undergone obligatory reoperation. Four patients who had undergone a BVR have required reoperation on the TV. In 2 patients, reoperation represented re-replacing a valve prosthesis that had been placed during the initial operation, and 2 additional patients required TV replacement for significant tricuspid regurgitation. In 2 patients a bidirectional Glenn procedure was added at the time of TV replacement. The Kaplan-Meier estimate of freedom from reoperation was $74 \% \pm 10 \%$ at 15 years for patients who underwent BVR $(\mathrm{n}=29)$ (Figure 5).

\section{Arrhythmias and Functional Status}

Although 4 neonates had malignant tachyarrhythmias before neonatal BVR, only 1 patient is taking prophylactic antiarrhythmic medication at the discretion of his cardiologist. All survivors are in New York Heart Association class I or II. The first neonate in the series currently plays football on his high school team as a wide receiver. His most recent echocardiogram indicates normal biventricular function with trivial TV regurgitation.

\section{DISCUSSION}

EA is a particularly difficult congenital heart lesion to manage in the severely symptomatic neonate. Early survival has historically remained dismal despite various surgical and nonsurgical options. ${ }^{3,4,6}$ Even when EA is diagnosed

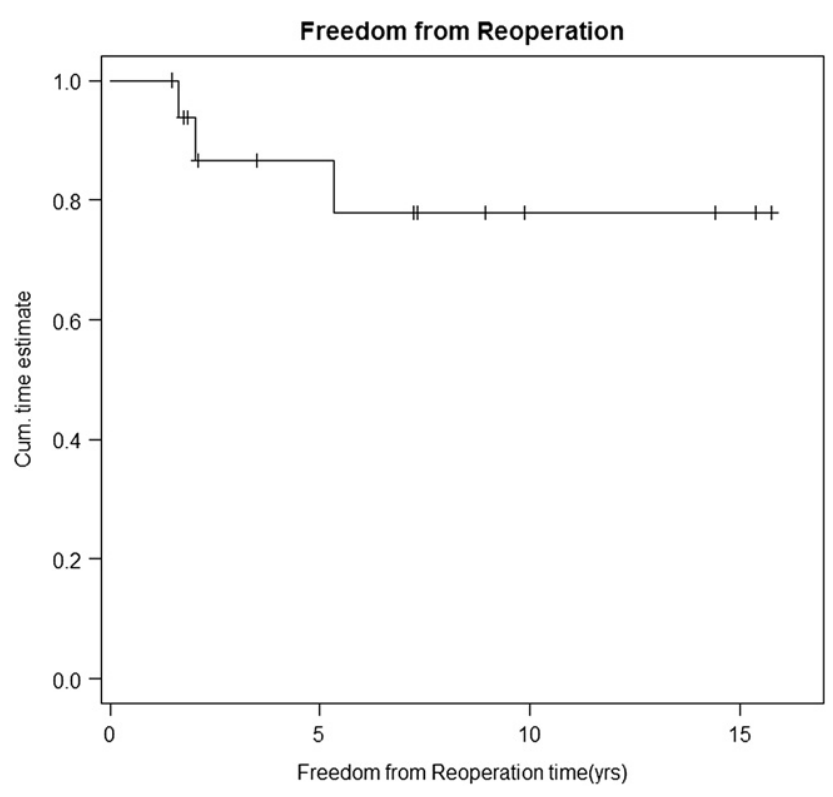

FIGURE 5. Freedom from reoperation for patients having biventricular repair $(\mathrm{n}=29)$. in infancy beyond the first month of life, the mortality risk is 8 times higher than in patients receiving the diagnosis after 1 year of age. ${ }^{3}$ Recent data from the Pediatric Health Information System database have shown that even less symptomatic neonates who were treated medically in institutions in the United States between 2002 and 2006 had an early mortality of $22 \% .^{20}$ This underscores the tenuous and unpredictable course of the disease in neonates, as opposed to older infants and children. ${ }^{5,7,11}$

In this series of symptomatic neonates referred for surgical intervention, $45 \%$ were initially managed nonsurgically. However, $47 \%$ of these required surgery during early infancy. These data support the observation that about $50 \%$ of acyanotic symptomatic neonates with EA will die within the first year of life without surgical intervention. ${ }^{6}$ For this subset of patients $(n=9)$, which represents one of the largest reported series of young infants undergoing surgery for EA, our early and late survival was $100 \%$. This is significantly better than the $50 \%$ early survival recently reported by the European Congenital Heart Surgeons multicenter trial for infants with EA having surgery between 2002 and 2005. ${ }^{21}$

In our experience with severely symptomatic neonates who remained critically ill and required surgery during the neonatal period $(\mathrm{n}=23)$, we were able to achieve a BVR in $86 \%$. This is in contrast to the experience of both Reemt$\operatorname{sen}^{16}$ and Shinkawa, ${ }^{22}$ who reported that they were able to achieve a BVR in only about $10 \%$ of their patients. The explanation for these differences in surgical approach may relate to morphologically different populations or institutional bias. Needless to say, in this subset of critically ill neonates with EA, the predicted early mortality without surgery approximates $100 \%{ }^{4,6}$ Our strategy of selective BVR resulted in a very encouraging early survival of $78.1 \%$ overall and $69.5 \%$ for the neonates. For the neonates without anatomic PA, early survival was $90 \%$, whereas those neonates with associated PA had an early survival of $53.8 \%$. If one analyzes only those neonates with anatomic PA who had BVR, early survival was only $45.5 \%$. This is similar to the experience of Bove's group (Shinkawa and associates $^{22}$ ) who had a $25 \%$ early survival in a similar subset of neonates.

Although neonates with EA and anatomic PA clearly still represent the Achilles heel in critically ill neonates with EA, certain observations have been made that have altered our management strategy during the latter years of the study period: (1) The degree of tricuspid regurgitation seems inversely proportional to the diastolic dimension of the functional RV. When tricuspid regurgitation therefore is mild (1-2/4), we now advocate ligating the ductus, constructing a systemic-pulmonary shunt, and, if feasible, doing a very conservative open pulmonary valvotomy. All this is done without placing the patient on bypass. At 4 months of age, a bidirectional Glenn anastomosis is performed, and 
if the RV has developed, the ASD is partially closed and the RVOT is reconstructed with either a transannular patch or a homograft. (2) If significant tricuspid regurgitation is present, generally the functional RV is much larger but the attachments of the TV leaflet may be very close to the atretic RVOT. If this is the case, replacing the RVOT with a homograft may further compromise the integrity of the TV. We would therefore advocate a Starnes procedure using a fenestrated patch. (3) On the other hand, if the functional $\mathrm{RV}$ is reasonable in size and the TV amenable to repair (as is often the case), we would reconstruct the RVOT with a small (7-9 $\mathrm{mm}$ ) aortic homograft, then repair the TV, and partially close the ASD as previously described.

In 2 neonates with anatomic PA who underwent transannular patch and required extracorporeal membrane oxygenator support postoperatively, reoperation was performed for $\mathrm{RV}$-pulmonary artery conduit placement using a small homograft. In both cases, the patients were hemodynamically improved and would certainly have survived except for subsequent comorbidities. Therefore, using this current management algorithm, we have now managed 4 consecutive neonates with EA and PA over the past 2 years without early or late mortality. Our current algorithm for surgical management is illustrated in Figure 6.

Another difference in our current management strategy concerns those patients with wide open pulmonary regurgitation and tricuspid regurgitation with cardiogenic shock; today we would take this patient directly to the operating room to ligate the patent ductus arteriosus, place a small peripheral Blalock-Taussig shunt, and incompletely ligate the main pulmonary artery without the aid of cardiopulmonary bypass. The patient would be taken for reoperation 3 to 7 days later once the pulmonary vascular resistance had been lowered and the anatomy and morphology more fully evaluated.

Our early and late survivals compare favorably with those of other recent studies. ${ }^{3,6}$ In a multicenter study from the European Congenital Heart Surgeons Association database, the operative mortality for any surgical intervention during the neonatal period was $53.8 \%{ }^{20}$ In a nonconsecutive follow-up series of 16 patients, Reemtsen and associates ${ }^{16}$ reported an early mortality of $24 \%$ for neonates with EA who

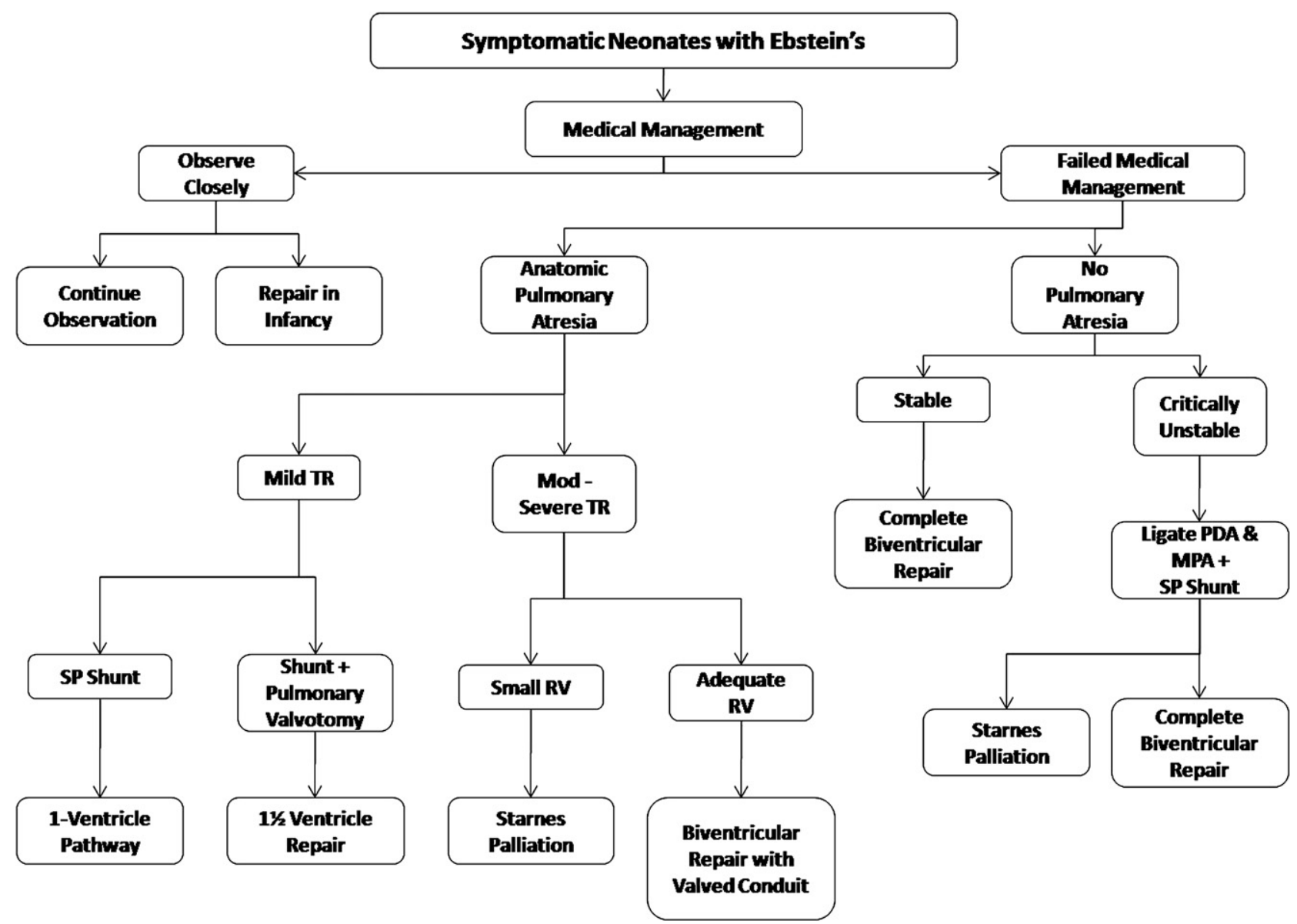

FIGURE 6. Surgical algorithm for symptomatic neonates with Ebstein anomaly. TR, Tricuspid regurgitation; $P D A$, patent ductus arteriosus; $M P A$, main pulmonary artery; $S P$, systemic-pulmonary. 
underwent single-ventricle palliation. Recently, Shinakawa and colleagues ${ }^{22}$ reviewed their experience with surgical management of 24 neonates with EA. Their survival estimates for patients treated with the Starnes RV exclusion procedure single-ventricle palliation was $63 \%$ at 10 years. In contrast, the 10 -year survival was $76 \%$ for those patients in whom placing a systemic-pulmonary shunt was sufficient to allow them to survive early infancy.

We have shown that TV repair for neonatal EA is durable with $74 \%$ long-term freedom from reoperation. In the majority of patients, the degree of TV regurgitation has remained stable and mild over the follow-up period. Generally, the patients have excellent functional status as exemplified by the first patient who currently is a track-and-field athlete and a running back on the high school football team 16 years after neonatal BVR. More comprehensive exercise testing is necessary to determine whether the functional status is reflective of a favorable maximum volume of oxygen use. From the echocardiograms done at late follow-up, it seems as though the TV repair has not resulted in progressive TV stenosis, and no patient has needed reintervention for TV stenosis in our experience.

The low incidence of arrhythmias during the follow-up period remains an interesting observation. We have previously speculated that arrhythmias in patients with EA may be partly related to chronic right-sided volume overload and that early repair with correction of this hemodynamic impropriety may result in less than expected arrhythmias. This needs further evaluation but remains an encouraging aspect of early repair.

Neonatal EA continues to be a challenging surgical problem. BVR for neonatal EA provides good long-term survival and freedom from reoperation, particularly in those patients in whom a competent TV repair is achieved.

\section{References}

1. Epstein ML. Congenital stenosis and insufficiency of the tricuspid valve. In: Allen HD, Clark EB, Gutgesell HP, Driscoll DJ, eds. Moss and Adams' heart disease in infants, children, and adolescents, Vol 2, 6th ed. Philadelphia: Lippincott Williams and Wilkins; 2001, p. 810-819.

2. Dearani JA, Danielson GK. Ebstein's Anomaly. In: Sellke FW, del Nido PJ, Swanson SJ, eds. Sabiston and Spencer's surgery of the chest, Vol 2, 7th ed. Philadelphia: Elsevier Saunders; 2005, p. 2219-2231.

3. Kapusta L, Eveleigh PM, Poulino S, Rijlaarsam ME, du Marchie Sarvass GJ, Strengers JL, et al. Ebstein's anomaly: factors associated with death in child- hood and adolescence: a multi-centre, long-term study. Eur Heart J. 2007;28 2661-6.

4. Celermajer DS, Dodd SM, Greenwald SE, Wyse RK, Deanfield JE. Morbid anatomy in neonates with Ebstein's anomaly of the tricuspid valve. J Am Coll Cardiol. 1992;19:1049-53.

5. Carpentier A, Chauvaud S, Mace L, Relland J, Mihaileanu S, Marino JP, et al. A new reconstructive operation for Ebstein's anomaly of the tricuspid valve. $J$ Thorac Cardiovasc Surg. 1988;Jul 96:92-101.

6. Celermajer DS, Cullen S, Sullivan ID, Spiegelhalter DJ, Wyse RK, Deanfield JE Outcome in neonates with Ebstein's anomaly. J Am Coll Cardiol. 1992;19: 1041-6.

7. Chauvad S. The tricuspid valve in Ebstein's anomaly: what should be done on the valve and on the right ventricle? Isr J Med Sci. 1996;32:844-5.

8. Andrews RE, Tibby SM, Sharland GK, Simpson JM. Prediction of outcome of tricuspid valve malformations diagnosed during fetal life. Am J Cardiol. 2008; 101:1046-50.

9. Starnes VA, Pitlick PT, Bernstein D, Griffin ML, Choy M, Shumway NE. Ebstein's anomaly appearing in the neonate. J Thorac Cardiovasc Surg. 1991; 101:1082-7.

10. Sano S, Ishino K, Kawada M, Kasahara S, Kohmoto T, Takeuchi M, et al. Total right ventricular exclusion procedure: an operation for isolated congestive right ventricular failure. J Thorac Cardiovasc Surg. 2002;123:640-7.

11. Boston US, Dearani JA, O'Leary PW, Driscoll DJ, Danielson GK. Tricuspid valve repair for Ebstein's anomaly in young children: a 30-year experience. Ann Thorac Surg. 2006;81:690-6.

12. Knott-Craig CJ, Overholt ED, Ward KE, Razook JD. Neonatal repair of Ebstein's anomaly: indications, surgical technique, and medium-term follow-up. Ann Thorac Surg. 2000;69:1505-10.

13. Knott-Craig CJ, Overholt ED, Ward KE, Ringewald JM, Baker SS, Razook JD. Repair of Ebtsein's anomaly in the symptomatic neonate: an evolution of technique with 7-year follow-up. Ann Thorac Surg. 2002;73: 1786-93.

14. Knott-Craig CJ, Goldberg SP, Overholt ED, Colvin EV, Kirklin JK. Repair of neonates and young infants with Ebstein's anomaly and related disorders. Ann Thorac Surg. 2007;84:587-93.

15. Chen JM, Mosca RS, Altmann K, Printz BF, Targoff K, Mazzeo PA, et al. Early and medium term results for repair of Ebstein's anomaly. $J$ Thorac Cardiovasc Surg. 2004;127:990-8.

16. Reemtsen BL, Fagan BT, Wells WJ, Starnes VA. Current surgical therapy for Ebstein's anomaly in neonates. J Thorac Cardiovasc Surg. 2006;132:1285-90.

17. Knott-Craig CJ. Management of neonatal Ebstein's anomaly. Op Tech Thorac Cardiovasc Surg. 2008;13:101-8.

18. Augustin N, Schmidt-Habelmann P, Wottke M, Meisner H, Sebening F. Results after surgical repair of Ebstein's anomaly. Ann Thorac Surg. 1997;63:1650-6.

19. Knott-Craig CJ, Goldberg S. Management of neonatal Ebstein's anomaly. Semin Thorac Cardiovasc Surg. 2007;10:112-6.

20. Jones RC, Goldberg SP, Haddad L, Boston US, Chin TK, Kelsey RM, et al. Current trends in the management of neonates with Ebstein's anomaly. Ann Thorac Surg. In press.

21. Sarris GE, Giannopoulos NM, Tscoutsinos AJ, Chatziz AK, Kirvassilis G, Brawn WJ, et al. European Congenital Heart Surgeons Association: results of surgery for Ebstein's anomaly: a multicenter study from the European Congenital Heart Surgeons Association. J Thorac Cardiovasc Surg. 2006; 132:50-7.

22. Shinkawa T, Polimenakos AC, Gomez-Fifer CA, Charpie JR, Hirch JC, Devaney EJ, et al. Management and long-term outcome of neonatal Ebstein's anomaly. J Thorac Cardiovasc Surg. 2010;139:354-8. 